\title{
Enablers and Barriers of Civil Military Relations in India: An Interpretive Structural Modeling Approach
}

\author{
Sanjeev Sharma and Poornima Tapas
}

Symbiosis International (Deemed University),Pune - 411020, Maharashtra, India; sansharma37@gmail.com Symbiosis Institute of Business Management, Pune - 411020, Maharashtra, India; poornimatapas@sibmpune.edu.in

\begin{abstract}
Background: Civil Military Relations (CMR) is a complex mix of explicit, implicit, traditions, precedence, evolutions, powers forming part of the social contract that underpins the country`s governance. Arena of CMR is strategic. There are a few factors known as CMR Enablers and Barriers (EBs), which affect CMR. Objective: To study the basic relationships amongst the shortlisted EBs. Also to understand the driver and driven EBs. Methods and Analysis: Interpretive Structural Modeling (ISM) technique with Micmac Analysis was used. The inter-se and inter relationships between the EBs was derived. EBs was further categorized, based on their ability to drive others or their dependence on others. Ultimately, how critical each factor is for the success of CMR was identified. Findings: Legacy, Leadership and National Interest were found to be most critical EBs since they have individual effect on building a dynamic CMR which is of immense importance in Nation building by ensuring cohesiveness among Civil and Military parlors. Conclusion/Further Study: Enablers and Barriers are the key in the effective CMR implementation process. Conclusively, all ten EBs are relevant although they exhibit a varying degree of relative importance. Future study, could quantify the framework obtained from ISM model, using Analytical Hierarchy Process (AHP).
\end{abstract}

Keywords: Barriers, Civil-Military Relations, Enablers, Interpretive Structural Modeling (ISM), Micmac Analysis

\section{Introduction}

CMR consists of relationship between two players namely the Armed Forces and the society. The role of Armed Forces is to protect the civil society at large. Constitution clearly demarcates the power entrusted to these two players. Various thinkers over the years and in specific Sun Tzu and Clausewitz opined that military was a servant of the State. While others contested as to which type of control was suitable for the nation in larger interest of the society. Contributions of great thinkers like Samuel Huntington and Morris Janowitz are noteworthy and hold relevance till date. The success of national security policy has a direct bearing on effective CMR which further impacts the internal stability of a nation state.

The twenty-first century has seen multiple sociopolitical-economic-cultural changes resulting in transforming the pre-defined work culture of the Armed Forces and Civil Society at large. Economic and human security segments are now domain of both of them. New roles and responsibilities if not clearly demarcated, will lead to situations detrimental to the progress of the nation in long run.

Interpretive Structural Modeling (ISM) is a tool to handle complex interrelated issues to define relative importance. Micmac analysis is a tool that structures the pooling of ideas describing a system using a matrix which combines the constituent components of the system. It identifies the main variables which are both influential and dependent: those which are essential to the evolution of the system.

\section{Objective}

This study will focus on CMR in India using ISM Technique by listing the key Enablers and Barriers and studying their relationship. 


\subsection{Specific Areas for Review}

In depth understanding of CMR, its enablers and barriers, related issues published so far and to analyze a comprehensive relationship using ISM.CMR in context of an institutional approach is linked to power struggles and social cohesion 1 .

\subsection{Identifying the Enablers and Barriers}

Extensive literature review found out Enablers and Barriers of CMR which are listed in subsequent paragraphs:

\subsubsection{Enablers}

Table 1 gives out the list of enablers.

Table 1. Enablers

\begin{tabular}{|c|c|}
\hline References & Enablers \\
\hline$\underline{2}$ & $\begin{array}{l}\text { Strategic, operational, organizational, and } \\
\text { social sets of decisions. }\end{array}$ \\
\hline$\underline{3}$ & Shared responsibilities \\
\hline$\underline{4}$ & Inter-Provincial harmony \\
\hline$\underline{5}$ & $\begin{array}{l}\text { Formal arrangements and informal practices, } \\
\text { Personalities of leaders and external variables }\end{array}$ \\
\hline$\underline{6}$ & $\begin{array}{l}\text { Political culture of society and the } \\
\text { politicization in social forces and state } \\
\text { agencies }\end{array}$ \\
\hline$\underline{7-8}$ & $\begin{array}{l}\text { Level of modernization, socio-economic } \\
\text { performance of the civilian regime, or the } \\
\text { threat environment }\end{array}$ \\
\hline$\underline{9}$ & Dynamic leadership \\
\hline$\underline{10}$ & Exchange relationships \\
\hline$\underline{11}$ & $\begin{array}{l}\text { Transformation of the international } \\
\text { security system, coupled with political } \\
\text { democratization. } \\
\text { Society's attitude toward the military. }\end{array}$ \\
\hline$\underline{12}$ & $\begin{array}{l}\text { Political Culture, Degree of Democratic Wave, } \\
\text { Military Professionalism, Support from the } \\
\text { State }\end{array}$ \\
\hline$\underline{13}$ & Game of strategic interaction \\
\hline$\underline{14}$ & $\begin{array}{l}\text { Dialogue, accommodation, and shared } \\
\text { values or objectives among the military, } \\
\text { the political elites and society, Active } \\
\text { agreement, established by legislation, decree, } \\
\text { or constitution, or based on longstanding } \\
\text { historical and cultural values. }\end{array}$ \\
\hline$\underline{15}$ & $\begin{array}{l}\text { Cultural and historical context, Partnership or } \\
\text { integration model }\end{array}$ \\
\hline
\end{tabular}

\begin{tabular}{|c|l|}
\hline References & \multicolumn{1}{|c|}{ Enablers } \\
\hline$\underline{16}$ & $\begin{array}{l}\text { Political neutrality, democratic control, and } \\
\text { social impartiality of the armed forces. }\end{array}$ \\
\hline$\underline{17}$ & Creating politically legitimate institutions \\
\hline$\underline{18}$ & $\begin{array}{l}\text { Transformation in CMR due to the new } \\
\text { global security challenges and operational } \\
\text { environment }\end{array}$ \\
\hline
\end{tabular}

\subsubsection{Barriers}

Table 2. gives out the list of Barriers.

Table 2. Barriers

\begin{tabular}{|c|c|}
\hline References & Barriers \\
\hline$\underline{19}$ & $\begin{array}{l}\text { Trust between civilian bureaucrats in the } \\
\text { Defense Ministry and the uniformed military }\end{array}$ \\
\hline$\underline{20}$ & $\begin{array}{l}\text { Strategic uncertainty and fiscal austerity, Rights } \\
\text { allocation, Burden redistribution }\end{array}$ \\
\hline$\underline{21}$ & Societal, economic, and operational reasons \\
\hline$\underline{5}$ & Control mechanisms. \\
\hline$\underline{22}$ & Strategic blunders in functioning \\
\hline$\underline{6}$ & $\begin{array}{l}\text { Salience of power struggles and social } \\
\text { cohesion, Economic stability or addressing } \\
\text { social disorder and the concomitant } \\
\text { polarization of society and corruption }\end{array}$ \\
\hline$\underline{23}$ & $\begin{array}{l}\text { Division of responsibility in the formulation } \\
\text { and implementation of defence and security } \\
\text { policy, Institutional fault-lines, differing } \\
\text { organizational cultures, priorities and } \\
\text { approaches, and a dynamically evolving } \\
\text { operational environment. }\end{array}$ \\
\hline$\underline{24}$ & Lack of communication \\
\hline$\underline{25-26}$ & Foreign policy decision making \\
\hline$\underline{11}$ & $\begin{array}{l}\text { Pay towards defence, particularly higher taxes } \\
\text { or reductions in other areas of public spending }\end{array}$ \\
\hline$\underline{27}$ & Vacuum of authority \\
\hline$\underline{28}$ & $\begin{array}{l}\text { Cultural and geographic isolation, } \\
\text { Civil leadership lacking the most basic } \\
\text { understanding of military institutional } \\
\text { knowledge }\end{array}$ \\
\hline$\underline{29}$ & $\begin{array}{l}\text { "unequal dialogue." between civilian and } \\
\text { military establishment }\end{array}$ \\
\hline$\underline{30}$ & Politico-bureaucratic nexus \\
\hline$\underline{31}$ & $\begin{array}{l}\text { Cultural, demographic, policy preference, and } \\
\text { institution }\end{array}$ \\
\hline$\underline{32}$ & Politico-military histories of nations \\
\hline$\underline{33}$ & Complexity of the policy process \\
\hline$\underline{34}$ & Societies' perception. \\
\hline
\end{tabular}


Table 3. Summary of research work for short listing of CMR Enablers/Barriers (EBs)

\begin{tabular}{|c|c|c|c|c|c|c|c|c|c|c|}
\hline $\begin{array}{l}\text { Enablers/ } \\
\text { Barriers }\end{array}$ & $\begin{array}{l}\text { Orga- } \\
\text { nization } \\
\text { Struc- } \\
\text { ture }\end{array}$ & Legacy & $\begin{array}{l}\text { Leader- } \\
\text { ship }\end{array}$ & $\begin{array}{l}\text { Decision } \\
\text { Making } \\
\text { Process } \\
\& \\
\text { Control }\end{array}$ & $\begin{array}{l}\text { Indi- } \\
\text { vidual } \\
\text { Beha- } \\
\text { vior }\end{array}$ & $\begin{array}{l}\text { Orga- } \\
\text { nization } \\
\text { Culture }\end{array}$ & $\begin{array}{l}\text { Morals \& } \\
\text { Ethics }\end{array}$ & $\begin{array}{l}\text { National } \\
\text { Interest }\end{array}$ & $\begin{array}{l}\text { Citizen } \\
\text { Aware- } \\
\text { ness }\end{array}$ & Policy \\
\hline Author & 1 & 2 & 3 & 4 & 5 & 6 & 7 & 8 & 9 & 10 \\
\hline 1 & $\checkmark$ & & & $\checkmark$ & & & & & & $\checkmark$ \\
\hline$\underline{19}$ & & $\checkmark$ & & & & $\checkmark$ & & $\checkmark$ & & \\
\hline$\underline{20}$ & $\checkmark$ & & $\checkmark$ & & & $\checkmark$ & & & & \\
\hline$\underline{2}$ & $\checkmark$ & $\checkmark$ & & $\checkmark$ & & $\checkmark$ & & & & $\checkmark$ \\
\hline$\underline{3}$ & $\checkmark$ & $\checkmark$ & & & & $\checkmark$ & & $\checkmark$ & & \\
\hline$\underline{4}$ & $\checkmark$ & $\checkmark$ & $\checkmark$ & & & $\checkmark$ & & $\checkmark$ & & $\checkmark$ \\
\hline$\underline{5}$ & $\checkmark$ & & $\checkmark$ & $\checkmark$ & & $\checkmark$ & & $\checkmark$ & $\checkmark$ & $\checkmark$ \\
\hline$\underline{35}$ & & $\checkmark$ & & & & & & $\checkmark$ & $\checkmark$ & $\checkmark$ \\
\hline$\underline{22}$ & $\checkmark$ & & $\checkmark$ & $\checkmark$ & & & & & & $\checkmark$ \\
\hline$\underline{6}$ & $\checkmark$ & $\checkmark$ & & & & $\checkmark$ & $\checkmark$ & $\checkmark$ & $\checkmark$ & \\
\hline$\underline{23}$ & $\checkmark$ & $\checkmark$ & $\checkmark$ & & & $\checkmark$ & & $\checkmark$ & & $\checkmark$ \\
\hline$\underline{7}$ & $\checkmark$ & $\checkmark$ & $\checkmark$ & & & $\checkmark$ & & $\checkmark$ & & $\checkmark$ \\
\hline 9 & $\checkmark$ & $\checkmark$ & $\checkmark$ & & & $\checkmark$ & & $\checkmark$ & & $\checkmark$ \\
\hline$\underline{24}$ & $\checkmark$ & $\checkmark$ & $\checkmark$ & & & $\checkmark$ & & $\checkmark$ & & $\checkmark$ \\
\hline$\underline{25}$ & $\checkmark$ & & & $\checkmark$ & & & & & & $\checkmark$ \\
\hline$\underline{26}$ & $\checkmark$ & & & $\checkmark$ & & & & & & $\checkmark$ \\
\hline$\underline{10}$ & $\checkmark$ & $\checkmark$ & $\checkmark$ & & & $\checkmark$ & & & & \\
\hline$\underline{11}$ & $\checkmark$ & & $\checkmark$ & & & & & $\checkmark$ & & $\checkmark$ \\
\hline$\underline{29}$ & & & $\checkmark$ & & & & & & & \\
\hline$\underline{28}$ & & $\checkmark$ & $\checkmark$ & & & & & $\checkmark$ & & \\
\hline$\underline{12}$ & & $\checkmark$ & $\checkmark$ & & & $\checkmark$ & & $\checkmark$ & $\checkmark$ & $\checkmark$ \\
\hline$\underline{29}$ & $\checkmark$ & & $\checkmark$ & & & $\checkmark$ & & $\checkmark$ & & $\checkmark$ \\
\hline$\underline{13}$ & $\checkmark$ & & & & & $\checkmark$ & & & & \\
\hline$\underline{30}$ & & $\checkmark$ & & & & & $\checkmark$ & $\checkmark$ & & \\
\hline$\underline{31}$ & & $\checkmark$ & & & & & & $\checkmark$ & & \\
\hline$\underline{32}$ & & $\checkmark$ & $\checkmark$ & & & & & $\checkmark$ & & \\
\hline$\underline{33}$ & $\checkmark$ & & & & & & & & & \\
\hline$\underline{34}$ & & $\checkmark$ & $\checkmark$ & & & & & $\checkmark$ & $\checkmark$ & $\checkmark$ \\
\hline$\underline{15}$ & $\checkmark$ & $\checkmark$ & $\checkmark$ & & $\checkmark$ & $\checkmark$ & $\checkmark$ & $\checkmark$ & $\checkmark$ & $\checkmark$ \\
\hline$\underline{16}$ & $\checkmark$ & $\checkmark$ & $\checkmark$ & & & $\checkmark$ & $\checkmark$ & & & \\
\hline$\underline{35-36}$ & $\checkmark$ & & $\checkmark$ & & & & & $\checkmark$ & & \\
\hline$\underline{25,37}$ & & & & $\checkmark$ & & $\checkmark$ & & $\checkmark$ & $\checkmark$ & $\checkmark$ \\
\hline
\end{tabular}


Interaction with experts and survey of literature helped shortlist various EBs. These have been highlighted; Refer Table 3.

\subsection{Research Gap}

Limited publications are available on the relationship between EBs of CMR and their impact for implementation in India.

\subsection{Research Objective}

The two objectives of this paper in Indian context are as follows:

1. To identify the enablers and barriers of CMR, and

2. To carry out ISM Modelling by Structuring of final outcome in a hierarchical order, finding their interse relationship, establishing Driving and Dependence Powers and then carrying out Level Partitions and Classifications.

\section{Research Design}

Research Design is discussed in the succeeding paragraph.

Experts Opinion Views of Senior Officers of the Bureaucracy, Pan Armed Forces, Seasoned Politicians, Academicians, Civil Society, Students undertaking various PG courses were taken in short listing the critical factors.

Respondents Primary source of data were Junior Officers of the Bureaucracy and Pan Armed Forces. Inputs were gathered through Questionnaire.

Sampling Technique and Sample Size Random sampling technique was used. A Sample Size of 300 was taken.

Method of Investigation Respondents were appropriately identified maintaining randomness.

Questionnaire Design The questionnaire uses fivepoint rating scale which was divided into five parts. Part 1 is related to CMR Evolution; Part 2 on National Interest; Part 3 is related to Leadership; Part 4 on Governance and Part 5 is related to Areas of Improvement in CMR.

\subsection{Interpretive Structural Modelling (ISM)}

The first step in ISM is to identify the variables, work out a subordinate relation, followed by developing a Structural Self-Interaction Matrix (SSIM) based on comparison of variables. Transitivity checks are carried post conversion of SSIM to a Reachability Matrix (RM). This is followed by developing a matrix model called ISM which involves partitioning of the elements. The details of CMR EBs that would be tested in the current research are tabulated, refer Table 4.

Table 4. CMR enablers/ barriers (EBs) shortlisted

\begin{tabular}{|c|l|}
\hline EB No. & Description \\
\hline 1. & Organization Structure \\
\hline 2. & Legacy \\
\hline 3. & Leadership \\
\hline 4. & Decision Making Process \& Control \\
\hline 5. & Individual Behavior \\
\hline 6. & Organization Culture \\
\hline 7. & Morals \& Ethics \\
\hline 8. & National Interest \\
\hline 9. & Citizen Awareness \\
\hline 10. & Policies \\
\hline
\end{tabular}

\subsection{Structural Self-Interaction Matrix (SSIM)}

SSIM is a result of interaction with a group of Pan Armed Forces and Civil Services officers. Relevance and grouping of shortlisted Enablers / Barriers were iterated based on their contextual relationship. The VAXO Matrix was then worked out, refer Table 5 .

\subsection{Reachability Matrix}

The next step involves evolution of Initial reachability matrix by binary substitution of $\mathrm{V}, \mathrm{A}, \mathrm{X}, \mathrm{O}$ by 0,1 respectively in the SSIM. Refer Table 6. 
Table 5. Structural self-interaction matrix (SSIM)

\begin{tabular}{|c|c|c|c|c|c|c|c|c|c|c|c|}
\hline \multirow{2}{*}{ EB No. } & \multirow{2}{*}{ Description } & \multicolumn{10}{|c|}{ EB Number } \\
\hline & & 10 & 9 & 8 & 7 & 6 & 5 & 4 & 3 & 2 & 1 \\
\hline 1. & Organization Structure & $\mathrm{A}$ & $\mathrm{O}$ & $\mathrm{A}$ & $\mathrm{O}$ & $\mathrm{A}$ & $\mathrm{V}$ & V & A & $\mathrm{A}$ & $\mathrm{X}$ \\
\hline 2. & Legacy & $\mathrm{V}$ & $\mathrm{V}$ & $\mathrm{O}$ & $\mathrm{V}$ & $\mathrm{V}$ & $\mathrm{V}$ & V & $\mathrm{V}$ & $\mathrm{X}$ & $\mathrm{V}$ \\
\hline 3. & Leadership & $\mathrm{V}$ & $\mathrm{V}$ & A & $\mathrm{V}$ & $\mathrm{V}$ & $\mathrm{V}$ & $\mathrm{V}$ & $\mathrm{X}$ & A & $\mathrm{V}$ \\
\hline 4. & Decision Making Process \& Control & A & A & A & A & A & A & $\mathrm{X}$ & A & A & A \\
\hline 5. & Individual Behavior & A & $\mathrm{X}$ & A & $\mathrm{X}$ & A & $\mathrm{X}$ & V & A & A & A \\
\hline 6. & Organization Culture & $\mathrm{X}$ & $\mathrm{X}$ & $\mathrm{A}$ & $\mathrm{X}$ & $\mathrm{X}$ & $\mathrm{V}$ & $\mathrm{V}$ & A & $\mathrm{A}$ & $\mathrm{V}$ \\
\hline 7. & Morals \& Ethics & $\mathrm{O}$ & A & A & $\mathrm{X}$ & $\mathrm{X}$ & $\mathrm{X}$ & V & A & A & $\mathrm{O}$ \\
\hline 8. & National Interest & $\mathrm{V}$ & $\mathrm{V}$ & $\mathrm{X}$ & $\mathrm{V}$ & $\mathrm{V}$ & $\mathrm{V}$ & V & V & $\mathrm{O}$ & $\mathrm{V}$ \\
\hline 9. & Citizen Awareness & $\mathrm{O}$ & $\mathrm{X}$ & A & $\mathrm{V}$ & $\mathrm{X}$ & $\mathrm{X}$ & $\mathrm{V}$ & A & $\mathrm{A}$ & $\mathrm{O}$ \\
\hline 10. & Policies & $\mathrm{X}$ & $\mathrm{O}$ & A & $\mathrm{O}$ & $\mathrm{X}$ & $\mathrm{V}$ & V & A & A & $\mathrm{V}$ \\
\hline
\end{tabular}

The rule for constructing the SSIM is:

V - EB(i) influences $\mathrm{EB}(\mathrm{j})$

A - EB(j) influences $E B(i)$

$\mathbf{X}$ - EB(i) and $\mathrm{EB}(\mathrm{j})$ will complement /influence each other

$\mathbf{O}-\mathrm{EB}(\mathrm{i})$ and $\mathrm{EB}(\mathrm{j})$ are unrelated.

Table 6. Initial reachability matrix (Driving and Dependence Power)

\begin{tabular}{|c|c|c|c|c|c|c|c|c|c|c|c|c|}
\hline \multirow{2}{*}{ EB No. } & \multirow{2}{*}{ Description } & \multicolumn{10}{|c|}{ EB Number } & \multirow{2}{*}{$\begin{array}{c}\text { Driving } \\
\text { Power }\end{array}$} \\
\hline & & 10 & 9 & 8 & 7 & 6 & 5 & 4 & 3 & 2 & 1 & \\
\hline 1. & Organization Structure & 0 & 0 & 0 & 0 & 0 & 1 & 1 & 0 & 0 & 1 & 3 \\
\hline 2. & Legacy & 1 & 1 & 0 & 1 & 1 & 1 & 1 & 1 & 1 & 1 & 9 \\
\hline 3. & Leadership & 1 & 1 & 0 & 1 & 1 & 1 & 1 & 1 & 0 & 1 & 8 \\
\hline 4. & Decision Making Process \& Control & 0 & 0 & 0 & 0 & 0 & 0 & 1 & 0 & 0 & 0 & 1 \\
\hline 5. & Individual Behavior & 0 & 1 & 0 & 1 & 0 & 1 & 1 & 0 & 0 & 0 & 4 \\
\hline 6. & Organization Culture & 1 & 1 & 0 & 1 & 1 & 1 & 1 & 0 & 0 & 1 & 7 \\
\hline 7. & Morals \& Ethics & 0 & 0 & 0 & 1 & 1 & 1 & 1 & 0 & 0 & 0 & 4 \\
\hline 8. & National Interest & 1 & 1 & 1 & 1 & 1 & 1 & 1 & 1 & 0 & 1 & 9 \\
\hline 9. & Citizen Awareness & 0 & 1 & 0 & 1 & 1 & 1 & 1 & 0 & 0 & 0 & 5 \\
\hline 10. & Policies & 1 & 0 & 0 & 0 & 1 & 1 & 1 & 0 & 0 & 1 & 5 \\
\hline & Dependence Power & 5 & 6 & 1 & 7 & 7 & 9 & 10 & 3 & 1 & 6 & 55 \\
\hline
\end{tabular}

The rule for substitution to be followed is as follows:

1. All Vs will be substituted by 1 and the reciprocating A will be substituted by 0 ;

2. All As will be substituted by 0 and the reciprocating $V$ will be substituted by 1 ; and

3. All Xs will be substituted by 1 and All Os will be substituted by 0 . 


\subsection{Transitivity and Final Reachability Matrix}

ISM approach is based on expert opinion, conceptual inconsistency is detected in a qualitative way, in case of one such complex relationships. By means of inference, few cells of initial reachability matrix are filled up in order to arrive at final reachability matrix. By principle of transitivity, if relationship exists between variable ' $i$ ' \& ' $j$ ' and ' $j$ ' \& ' $k$ ', then variable ' $i$ ' is necessarily related to ' $k$ '. Subsequently, the final reachability matrix is developed after incorporating the transitivity concept in Table 6 and is presented in Table 7 wherein entries marked $\dagger$ show the transitivity.

\subsection{Level Partitioning the Final Reachability Matrix}

A structural model is then worked out based on results of the final reachability matrix. A series of partitions, which are induced by the reachability matrix on the set and subset of different variables are then created. The reachability set and antecedent set for each variable are established from the final reachability matrix (Table 8).

Table 7. Final reachability matrix (Driving \& Dependence Power)

\begin{tabular}{|c|c|c|c|c|c|c|c|c|c|c|c|c|}
\hline \multirow{2}{*}{ EB No. } & \multirow{2}{*}{ Description } & \multicolumn{10}{|c|}{ EB Number } & \multirow{2}{*}{$\begin{array}{c}\text { Driving } \\
\text { Power }\end{array}$} \\
\hline & & 10 & 9 & 8 & 7 & 6 & 5 & 4 & 3 & 2 & 1 & \\
\hline 1. & Organization Structure & 0 & 0 & 0 & 0 & 0 & 1 & 1 & 0 & 0 & 1 & 3 \\
\hline 2. & Legacy & 1 & 1 & 0 & 1 & 1 & 1 & 1 & 1 & 1 & 1 & 9 \\
\hline 3. & Leadership & 1 & 1 & 0 & 1 & 1 & 1 & 1 & 1 & 0 & 1 & 8 \\
\hline 4. & Decision Making Process \& Control & 0 & 0 & 0 & 0 & 0 & 0 & 1 & 0 & 0 & 0 & 1 \\
\hline 5. & Individual Behavior & 0 & 1 & 0 & 1 & 0 & 1 & 1 & 0 & 0 & 0 & 4 \\
\hline 6. & Organization Culture & 1 & 1 & 0 & 1 & 1 & 1 & 1 & 0 & 0 & 1 & 7 \\
\hline 7. & Morals \& Ethics & 0 & 0 & 0 & 1 & 1 & 1 & 1 & 0 & 0 & 0 & 4 \\
\hline 8. & National Interest & 1 & 1 & 1 & 1 & 1 & 1 & 1 & 1 & 0 & 1 & 9 \\
\hline 9. & Citizen Awareness & 0 & 1 & 0 & 1 & 1 & 1 & 1 & $\dagger 1$ & 0 & 0 & 6 \\
\hline 10. & Policies & 1 & 0 & 0 & 0 & 1 & 1 & 1 & 0 & 0 & 1 & 5 \\
\hline & Dependence Power & 5 & 6 & 1 & 7 & 7 & 9 & 10 & 4 & 1 & 6 & 56 \\
\hline
\end{tabular}

Table 8. Level partitions total number of iterations: 6

\begin{tabular}{|l|l|c|c|c|c|}
\hline EB No. & Description & Reachability Set & Antecedent Set & Intersection Level & Level \\
\hline 1. & Organization Structure & $1,4,5$ & $1,2,3,6,8,10$ & 1 & II \\
\hline 2. & Legacy & $1,2,3,4,5,6,7,9,10$ & 2 & 2 & VI \\
\hline 3. & Leadership & $1,3,4,5,6,7,9,10$ & $2,3,8,9$ & 3,9 & V \\
\hline 4. & Decision Making Process \& Control & 4 & $1,2,3,4,5,6,7,8,9,10$ & 4 & I \\
\hline 5. & Individual Behavior & $4,5,7,9$ & $1,2,3,5,6,7,8,9,10$ & $5,7,9$ & IV \\
\hline 6. & Organization Culture & $1,4,5,6,7,9,10$ & $2,3,6,7,8,9,10$ & $6,7,9,10$ & IV \\
\hline 7. & Morals \& Ethics & $4,5,6,7$ & $2,3,5,6,7,8,9$ & $5,6,7$ & III \\
\hline 8. & National Interest & $1,3,4,5,6,7,8,9,10$ & 8 & 8 & VI \\
\hline 9. & Citizen Awareness & $3,4,5,6,7,9$ & $2,3,5,6,8,9$ & $3,5,6,9$ & V \\
\hline 10. & Policies & $1,4,5,6,10$ & $2,3,6,8,10$ & 6,10 & IV \\
\hline
\end{tabular}

\begin{tabular}{|l|c|c|c|c|c|c|}
\hline Rounds & I & II & III & IV & V & VI \\
\hline Elimination & 4 & 1 & 6,7 & 9,10 & 3 & 2,8 \\
\hline
\end{tabular}

Note: 5 are knocked off since common to all. 


\subsection{ISM Digraph and Model}

Structural model is obtained after transitivity is applied to the final reachability matrix. Initial directed graph, or initial digraph is a diagrammatic representation of the relationship between any two EBs, as shown by an arrow which points from one to the other (Figure 1). Final digraph depicting the relationship among the CMR EBs. This is now used to develop further to generate the ISM-based model (Figure 2): ISM Based Model.

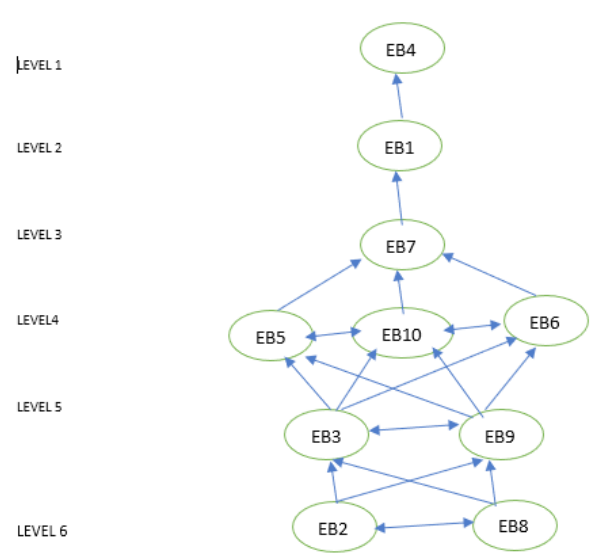

Figure 1. Final diagraph depicting the relationship among the CMR EBS.

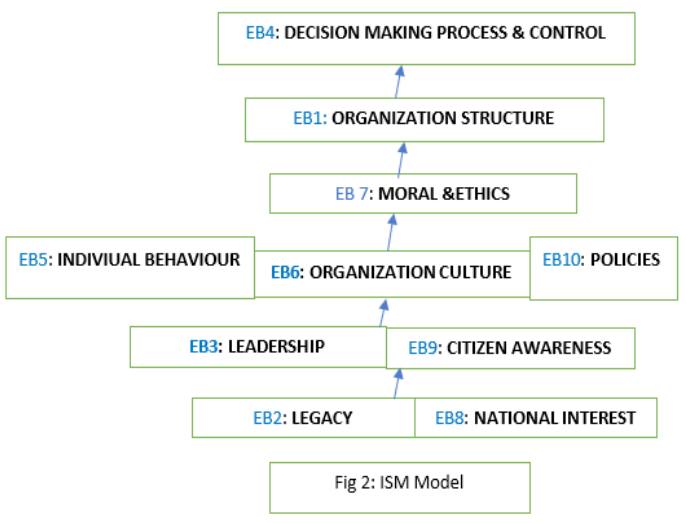

Figure 2. ISM model.

\section{MICMAC Analysis and Classification of EBs}

The driving power and dependence power of each of the EBs is found out using MICMAC (Figure 3) Cluster of KM Enablers and Barriers. The figure has four Quadrants.
First quadrant has Autonomous EBs; second quadrant conveys Dependent EBs; third quadrant includes Linkage EBs; fourth quadrant contains Driver EBs.

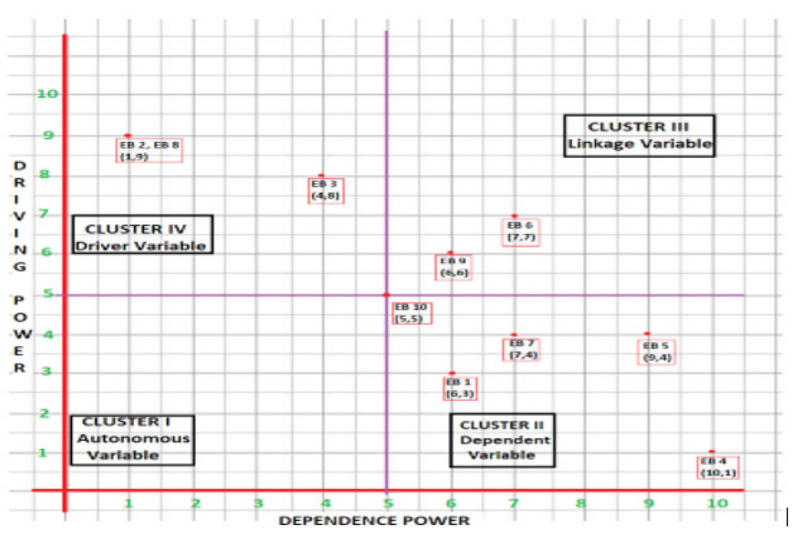

Figure 3. Cluster of CMR enablers and barriers.

The aim of this analysis is to identify the priorities of factors considered based on their inter-relationships. The driving power and dependence power is found out after classifying the EBs.

Quadrant I Autonomous: This quadrant consists of autonomous EBs (low driving power, low dependence power). These EBs are relatively disassociated from other; in the current context there are no EBs in this quadrant.

Quadrant II Dependent: This quadrant has EBs (low driving power, high dependence power). In the present case, EB1 (Organization Structure), EB4 (Decision Making Process and Control), EB5 (Individual Behavior), EB7 (Morals and Ethics) and EB10 (Policies) are in this category.

Quadrant III Linkage: In the Third quadrant EBs (high driving and dependence power). These EBs will have influence on other EBs with reverse effect on them. In this case: EB6 (Organization Culture), and EB 9 (Citizen Awareness) fall in this Category.

Quadrant IV Independent/ Drivers: The fourth quadrant contains independent EBs (very high driving power, low dependence power). In this case, EB2 (Legacy), EB3 (Leadership) and EB8 (National Interest) are in this category.

\section{Findings}

In reality, understanding the status or hierarchy of EBs indicate the modus operandi for successful CMR Implementation. 
EB 2 (Legacy), EB3 (Leadership) and EB8 (National Interest) are the most significant EB. Reasons for their strong driving power should be understood. Legacy remains unchanged with passage of time. Thenational interest is the goals and ambitions of a nation. Leadership is all about inspiring masses and leading from front. As seen from ISM model, Leadership in itself gets influenced by Legacy and National Interest. In the ISM Model, EB 2 (Legacy) and EB 8 (National Interest) are thus positioned at the lowest level (Level 6). This implies that these elements drive the CMR process. If and when they play a pivotal role, then success is guaranteed or else, barriers in effective CMR will occur.EB3 (Leadership) and EB9 (Citizen Awareness) are at Level 5. Both EB2 and EB8 influence and drive EB3 and EB 9. Thus, we infer that both National Interest and Legacy have a direct bearing on influencing the country's leadership as well as Citizen awareness.

EB5 (Individual Behavior), EB6 (Organization Culture) and EB10 (Policies) are at Level 4. Individual Behavior is the person's reaction to different situations by expressing different emotions like anger, happiness, love, etc. Well known Psychologist Kurt Lewin defined Individual Behavior as $\mathrm{B}=\mathrm{F}(\mathrm{P}, \mathrm{E})$, where, $\mathrm{B}-$ Behavior, F - Behavior Function, P - Person, and E - Environment around the person. Morals and Ethicsare the rules that govern which actions are right and which are wrong. They can be for all of society or an individual's beliefs. Organization culture is all about how members of an organization functions in changing environment and stiff competition.EB7 (Morals and Ethics) is at Level 3. EB5 (Individual Behavior), EB6 (Organization Culture), EB10 (Policies) and EB7(Morals and Ethics) are the links between Driver and Driven EBs.

EB1 (Organization Structure) is positioned at Level 2. Organization structure is about earmarking duties and responsibilities for future growth. Organization structure determines how the roles, power and responsibilities are assigned, controlled, and coordinated, and how information flows between the different levels of management.EB1 has weak driving power and strong dependence power.

EB4 (Decision Making Process and Control) is independently positioned at 1 respectively. EB4 has the highest Dependence power followed closely by EB5. Several factors influence decision making in Civil Military Relations. These factors include past experience, cognitive biases, age and individual differences, belief in personal relevance, and an escalation of commitment, influence what choices people make. Understanding the factors that influence decision making process is important to understanding what decisions are made. Since, in CMR the factors that influence the process may impact the outcomes. On the other side, Individual behavior is influenced by individual's attitude in personal as well as social life based on his/her abilities, Gender, Race and culture, Attribution, Perception and Attitude. Since dependence power of EB4 and EB5 is high, Drivers such as EB3 (Leadership) must lend itself to enable modify Individual Behavior and make decision making process more coherent.

EB4 (Decision Making Process and Control) with strong dependence power (highest) and weakest driving power is positioned at the uppermost level. This indicates that the drivers must ensure that each and every member involved in Decision making process both in Civil and Military setup is committed and accountable. Ownership of the decisions outcomes must be encouraged to pave way for better CMR keeping in mind the lessons learnt.

Since EB4 (Decision Making Process and Control) and EB1 (Organization Structure) are independently placed at Level 1 and 2 respectively. These are enablers, a tool, a facilitator and act as a catalyst.

In MICMAC Diagram (Figure 3), we notice that there is no autonomous EBs; this means that there are no weak drivers and weak dependents. Thus, it can be concluded that all the balance EBs are relevant and have relative degree of importance as critical success factors for CMR implementation.

\section{Conclusion and Future Directions}

Enablers and Barriers are the key in the CMR process. It can be concluded that all ten EBs are relevant irrespective of varying degree of relative importance. The three critical EBs are Legacy, Leadership and National Interest. They have individual effect on building a dynamic CMR which is of immense importance in Nation building by ensuring cohesiveness among Civil and Military parlors. Future research in this field could be carried out using Analytical Hierarchy Process (AHP).

\section{References}

1. Aaron B, Evan S. Coup Risk, Counterbalancing, and International Conflict, Security Studies. 2005; 14(1):14077. Crossref. 
2. Douglas LB. A Unified theory of civil-military relations, Armed Forces and Society. 1999; 26(1):7-26. Crossref.

3. Douglas LB. Patterns in liberal democratic civil-military relations, Armed Forces and Society. 2001; 27(4):525-40. Crossref.

4. Pakistan Constitution. Constitution of the Islamic Republic of Pakistan. As Amended by The Constitution Twenty Fourth Amendment Act; 1973.

5. Cilliler Y. Popular determinant on Civil-Military Relations in Turkey, Arab Studies Quarterly. 2016; 38(2):500-20. Crossref.

6. Dag R. The role of contesting Ideologies: Civil-Military relations in Turkey, Journal of Global Analysis. 2016; 6(2):157-77.

7. Finer SE. The Man on Horseback: The Role of the Military in Politics. Pall Mall: London; 1962. p. 1-305.

8. Huntington SP. Political Order in Changing Societies. Yale University Press: New Haven; 1968.

9. Gunness K, Finkelstein DM. Civil-military Relations in Today's China: Swimming in a New Sea Routledge: New York; 2007.

10. Levy Y. A revised model of civilian control of the military: The interaction between the republican exchange and the control exchange, Armed Forces and Society. 2012; 38(4):529-56. Crossref.

11. Laugesen H, Moyo G, Rupiya MR. The New African CivilMilitary Relations. The African Public Policy and Research Institute: Pretoria; 2015. p. 1-223.

12. Karim MA. Civil-Military Relations in Democratic South Asia: A Comparative Framework. The Korean Journal of Defense Analysis. 2016, 28 (2), pp. 277-297.

13. Feaver PD. Crisis as shirking: An agency theory explanation of the souring of American Civil-Military relations, Armed Forces and Society. 1998; 24(3):407-34. Crossref.

14. Schiff RL. Civil-Military relations reconsidered: A Theory of concordance, Armed Forces and Society. 1995; 22(1):7-10. Crossref.

15. Rebecca LS. The Military and Domestic Politics: A Concordance Theory of Civil-Military Relations. Routledge Taylor and Francis Group: New York; 2008.

16. Fravel MT. Towards civilian supremacy: Civil-Military relations in Taiwan's Democratization, Armed Forces and Society. 2002; 29(1):57-84. Crossref.

17. Edmunds T. British civil-military relations and the problem of risk, International Affairs. 2012; 88(2):1468-2346. Crossref.

18. Welch CE. Civilian Control of the Military: Theory and Cases from Developing Countries. 3rd Edition. State University of New York Press: Albany; 1976. p. 1-337.
19. Mukherjee A. Fighting, Separately: Jointness and CivilMilitary relations in India, Journal of Strategic Studies. 2012; 40(1):6-34.

20. Allen CD. Civil-military relations in transitions: behavior of senior military officers, Joint Force Quarterly. 2017; 86:49.

21. Cohen SA. The Israel defense forces: From a people army to a professional military-causes and implications, Armed Forces and Society. 1995; 21(2):237-54. Crossref.

22. Halberstam D. The Best and the Brightest. 20th Edition. Ballantine Books: New York; 1993. p. 1-720.

23. Edmunds T. British civil-military relations and the problem of risk, International Affairs. 2012; 88(2):265-82. Crossref.

24. Skelton I. The civil military gap need not become a chasm, Joint Force Quarterly. 2012; 64:61-65.

25. Snyder J. The ideology of the offensive: Military Decision Making and the Disasters of 1914. 1st Ed. Cornell Studies in Security Affairs; 1989. p. 1-272.

26. Civilian KD. Soldiers and strife: Domestic sources of international aggression, International Security. 1998; 23(1):40-107.

27. Diamond L, Plattner M. Introduction in Civil-Military Relations and Democracy. Johns Hopkins University Press: Baltimore; 1996.

28. Lewis C. A New Sparta: America's threatening civil-military gap, Kennedy School Review. 2011; 11:170-75.

29. Owens MT. What military officers need to know about civil military relations, Naval War College Review. 2012; 65(2):67-87.

30. Harsh VP. Civil military relations in India: Difficult Times, CLAWS Journal. 2008; 209-13.

31. Rahbek-Clemmensen J, Archer EM, Barr J, Hall C, Swain KEO. Conceptualizing the civil-military gap. armed forces and society. 2012; 38(4):669-78. Crossref.

32. Shukla R. Civil military relations in India, CLAWS Journal. 2012; 36:1-28.

33. Charles AS. Warriors and Politicians: US Civil-Military Relations under Stress. 1st Edition. Routledge Taylor and Francis Group: New York; 2006. p. 1-256. PMid: 16441203.

34. Jeffrey S. Central European Civil-Military Relations and NATO Expansion. National Defense University, Institute for National Strategic Studies; 1995. p. 1-4.

35. Desch MC. Civilian Control of the Military: The Changing Security Environment. Johns Hopkins University Press: Baltimore; 1999.

36. Aaron B. United we Stand? Divide-and-Conquer Politics and the Logic of International Hostility. State University of New York Press: Albany; 2005. p. 1-171.

37. Zanfir F. Civil-military relations in Crisis Management II, Revista Academiei Fortelor Terestre. 2012; 17(4):380-85. 